\title{
Morphologic study of nutrient foramina in dried tibia and its clinical implications
}

\author{
Jayaprakash $\mathbf{T}^{1}$ \\ ${ }^{1}$ Dr Jayaprakash T, Assistant Professor, Department of Anatomy, Father Muller Medical College, Mangalore, Karnataka, \\ India.
}

Address for Correspondence: Dr Jayaprakash T, Email: jp79@ rediffmail.com

\begin{abstract}
Introduction: Diaphyseal fractures of tibia cases are common in orthopaedics and traumatology department. While planning a bone graft for a patient with trauma or tumour resection, the vascularity of the left over bone in the donor site is important as it influences the choice of graft to be used. Methodology: The study was conducted on 50 adult dried tibiae. Diaphyseal nutrient foramina were identified by their elevated margins and by the presence of a distinct groove proximal to them. Foramen index was calculated. Results: All the foramina were present on the posterior surface. Most of the $(80 \%)$ nutrient foramina were present lateral to vertical line (17 on the right and 23 on the left side). Eight nutrient foramina were present on the vertical line. Only two nutrient foramina were present medial to vertical line. The mean foramen index between right and left tibiae was $32.99 \pm 1.87$ and $34.36 \pm 6.24$ respectively. Majority (82\%) of nutrient foramina were found on upper zone, $18 \%$ were observed on middle zone and none were found on the lower zone. Conclusion: Scarcity of nutrient foramina in the middle and lower $1 / 3^{\text {rd }}$ of the shaft indicates poor blood supply to this region of bone which may account for delayed union or non union of the fractures at the lower part of the bone.
\end{abstract}

Keywords: Tibia, Diaphyseal nutrient foramen, Foramen index, Bone graft, Non union

\section{Introduction}

The diaphyseal nutrient arteries enter the shaft through diaphyseal nutrient foramen (DNF) present on the shaft of long bone, the role of which is important in providing nutrition and growth of long bones [1]. The DNF in most cases is directed away from the growing end of the bone [2]. As stated, they 'seek the elbow and flee from the knee', indicate the direction of nutrient foramina in upper and lower limbs [2]. The nutrient foramina reflect the bone vascularity [3]. The knowledge of the position of DNF is of medico legal and clinical importance [4]. Medico legally, total length of the bone could be estimated by knowing ratio between the total length and distance of the nutrient foramina from the ends [4]. Diaphyseal fractures of tibia are common in orthopaedics and traumatology department. Fracture through the nutrient canal disrupts the blood flow in the nutrient artery, which may result in delayed union or non union of the fractured bone [2]. Vascularized bone graft is the preferred method used in bone

Manuscript received $6^{\text {th }}$ June 2016

Reviewed: $16^{\text {th }}$ June 2016

Author Corrected: $28^{\text {th }}$ June 2016

Accepted for Publication $16^{\text {th }}$ July 2016 reconstruction as it ensures the survival of both donor and recipient bones [6]. A good blood supply is essential for osteoblast and osteocyte survival [7]. The present study was aimed to analyse the number, location, direction of nutrient foramen in tibia, the knowledge of which would aid orthopaedicians in surgical procedures. Hence this study was undertaken.

Aims and objectives: To study the morphology and topography of nutrient foramina in adult tibia

\section{Materials and Methods}

- The study was conducted on 50 adult dried tibiae (20 right and 30 left). The dry bones were obtained from the osteology section of Anatomy department, Father Muller Medical College, Mangalore.

- The damaged bones and those with gross pathological deformities were excluded from the study.

- After side determinations, the nutrient foramina were observed in all bones. They were identified by 
their elevated margins and by the presence of a distinct groove proximal to them. Foramina at the ends of the bone were ignored.

- The nutrient foramina were studied with regards to the following data:

1. Number of foramen on the bone shaft.

2. Location of foramen in relation to the length of the shaft.

3. Size: Nutrient foramina smaller than the size of 24 gauge hypodermic needle were considered as secondary foramina and were not included for the study. Foramina equal to or larger than this were considered as dominant foramina.
4. Direction and obliquity: A fine stiff wire was used to confirm the direction and obliquity of the foramen.

Foramen index (FI) was calculated using Hughes formula [8].

$\mathrm{FI}=(\mathrm{DNF} / \mathrm{TL}) \times 100$

Where DNF: The distance between the nutrient foramen and proximal end of the bone and TL: Total bone length.

All measurements were done using osteometric board. The statistical data analysis was carried out using SPSS 17 (Statistical Package for social Sciences). The descriptive statistical analysis was performed, the range, mean, standard deviation calculated.

\section{Results}

In the examined 50 (20 right, 30 left) adult dried tibia, single nutrient foramen was observed in all of them. All the bones showed the nutrient foramina on the posterior surface directed away from the proximal end. In relation to vertical zones, majority $(82 \%)$ of nutrient foramina were found on upper zone, $18 \%$ were observed on middle zone and none were found on the lower zone (Table 1).

Table-1: Distribution of diaphyseal nutrient foramina in vertical zones.

\begin{tabular}{|c|c|c|c|c|}
\hline \multirow{2}{*}{ Side } & $\begin{array}{c}\text { Number of Tibia/ Number of } \\
\text { DNF }\end{array}$ & $\begin{array}{c}\text { Lengthwise } \\
\text { distribution }\end{array}$ & Number & \% \\
\hline \multirow{2}{*}{ Right } & 20 & Upper 1/3 & 16 & $80 \%$ \\
\cline { 2 - 5 } & & Middle 1/3 & 4 & $20 \%$ \\
\cline { 2 - 5 } & \multirow{2}{*}{ Left } & Lower 1/3 & 0 & $83.33 \%$ \\
\cline { 2 - 5 } & \multirow{2}{*}{ Total } & Upper 1/3 & 25 & $16.66 \%$ \\
\cline { 2 - 5 } & \multirow{2}{*}{50} & Middle 1/3 & 5 & - \\
\cline { 2 - 5 } & & Lower 1/3 & 0 & $82 \%$ \\
\cline { 2 - 5 } & & Upper 1/3 & 41 & $18 \%$ \\
\cline { 2 - 5 } & & Middle 1/3 & 9 & - \\
\hline
\end{tabular}

In relation to the vertical line, majority $(80 \%)$ of nutrient foramina were present lateral to vertical line (17 on the right and 23 on the left), $8(16 \%)$ nutrient foramina were present on the vertical line and Only $2(4 \%)$ nutrient foramina were present medial to vertical line (Table 2). The mean bone length of right tibia was $37.47 \mathrm{~cm} \pm 2.00$ and left tibia was 37.01 $\mathrm{cm} \pm 2.72$. The mean foramen index of right tibia was $32.99 \pm 1.87$ and left tibia was $34.36 \pm 6.24$ (Table 3).

Table 2: Location of nutrient foramina in relation to vertical line

\begin{tabular}{|c|c|c|c|c|c|}
\hline \multicolumn{6}{|c|}{ Location of nutrient foramina } \\
\hline \multicolumn{2}{|c|}{ Lateral to vertical line } & \multicolumn{2}{|c|}{ On the vertical line } & \multicolumn{2}{|c|}{ Medial to vertical line } \\
\hline Right & Left & Right & Left & Right & Left \\
\hline 17 & 23 & 2 & 6 & 1 & 1 \\
\hline
\end{tabular}


Table-3: Distance of nutrient foramina from the upper end of the bone and total bone length.

\begin{tabular}{|c|c|c|c|c|c|c|c|}
\hline \multirow{2}{*}{ Side } & \multirow{2}{*}{$\begin{array}{c}\text { No of } \\
\text { bone }\end{array}$} & $\begin{array}{c}\text { Distance (in cm) from the } \\
\text { upper end }\end{array}$ & \multicolumn{2}{c|}{$\begin{array}{c}\text { Total bone length } \\
\text { (in cm) }\end{array}$} & \multicolumn{2}{c|}{ FI } \\
\cline { 3 - 8 } & & Mean & SD & Mean & SD & Mean & SD \\
\hline Right & 20 & 12.36 & 0.92 & 37.47 & 2.00 & 32.99 & 1.87 \\
\hline Left & 30 & 12.41 & 1.65 & 37.01 & 2.72 & 34.36 & 6.24 \\
\hline
\end{tabular}

Fig-1: Distribution of nutrient foramina in relation to vertical line

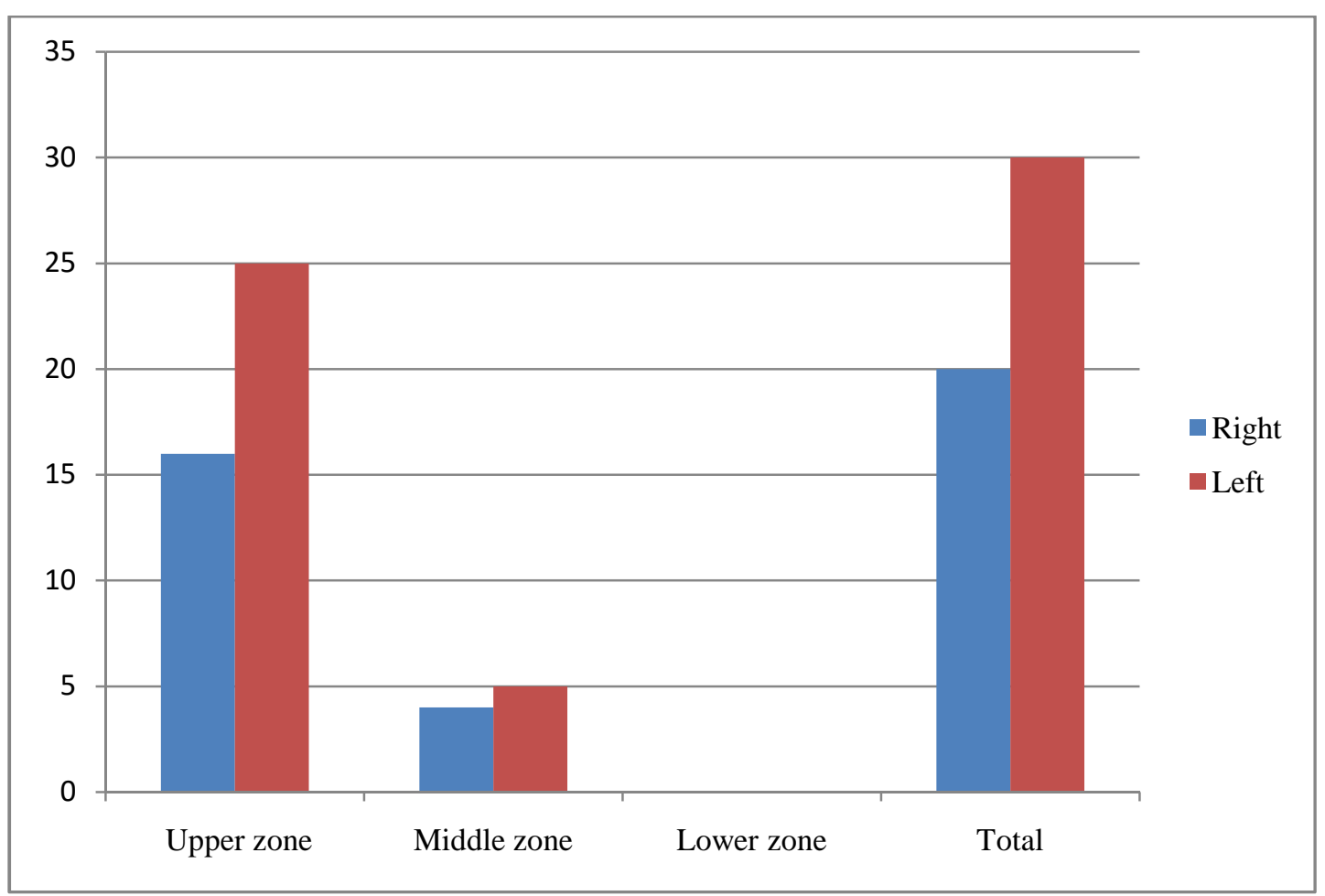

Fig 2: Distribution of nutrient foramina in vertical zones

\section{Discussion}

Injury to the nutrient artery increases the chances of delayed union or non union of the fractured bone. So the morphological knowledge of nutrient foramina is important for orthopaedic surgeons undertaking an open reduction of a fracture [9]. In our study, single nutrient foramina were observed on all the bones. The results correlate with study of Swati Gandhi [4]. Similar studies done in south Indian region have reported few double DNF (Udaya [9]: 7.14\%, Vrinda [2]: 2\%) (Table 4).

Table-4: Number of nutrient foramina in tibia shaft by different authors with special reference to the present study

\begin{tabular}{|c|c|c|c|}
\hline Author & Single NF & Double NF & Region \\
\hline Present study & $50 / 50$ & $0 / 50$ & Coastal Karnataka \\
\hline Vrinda [2] & $49 / 50$ & $1 / 50$ & North India \\
\hline Swati Gandhi [4] & $100 / 100$ & $0 / 100$ & Salem south \\
\hline Udaya [9] & $130 / 140$ & $10 / 140$ & \\
\hline
\end{tabular}


Table -5: Comparison of distribution of nutrient foramina with respect to vertical line.

\begin{tabular}{|c|c|c|c|c|}
\hline \multirow{2}{*}{ Author } & & \multicolumn{3}{|c|}{ Situation of nutrient foramina } \\
\cline { 2 - 5 } & $\begin{array}{c}\text { Lateral to } \\
\text { vertical line }\end{array}$ & $\begin{array}{c}\text { On the vertical } \\
\text { line }\end{array}$ & $\begin{array}{c}\text { Medial to vertical } \\
\text { line }\end{array}$ & Region \\
\hline Present & $40(80 \%)$ & $8(16 \%)$ & $2(4 \%)$ & Coastal Karnataka \\
\hline Udaya [9] & $99(77.34 \%)$ & $17(13.28 \%)$ & $12(9.37 \%)$ & Salem south \\
\hline Vrinda [2] & $35(70 \%)$ & $7(14 \%)$ & $8(16 \%)$ & Coastal Karnataka \\
\hline Swati Gandhi [4] & $89(89 \%)$ & - & $11(11 \%)$ & Amritsar \\
\hline
\end{tabular}

Table-6: Comparison of location of nutrient foramina with respect to vertical zones.

\begin{tabular}{|c|c|c|c|c|}
\hline Side & Upper & Middle & Lower & Total \\
\hline Present study & $41(82 \%)$ & $9(18 \%)$ & 0 & 50 \\
\hline Swati Gandhi [4] & 100 & 0 & 0 & 50 \\
\hline Vrinda [2] & $45(90 \%)$ & $5(10 \%)$ & 0 & 210 \\
\hline Longia [10] & $193(91.90 \%)$ & $17(8.09 \%)$ & 0 & 0 \\
\hline
\end{tabular}

In our study, the mean bone length on right and left sides were $37.47 \mathrm{~cm} \pm 2.00$ and $37.01 \mathrm{~cm} \pm 2.72$ respectively. Udaya et al. [9] reports mean length of right tibia as $35.23 \mathrm{~cm} \pm 2.401$ and mean length of left tibia as $35.91 \mathrm{~cm} \pm 2.110$. The distance between the nutrient foramen and the highest point of intercondylar eminence on the right side was $12.36 \pm 0.92$ and on left it was $12.41 \pm 1.65$. Udaya et al. [9] reports the distance between the nutrient foramen and the highest point of intercondylar eminence on right side to be $10.79 \mathrm{~cm} \pm 1.565$, and on left side to be $11.30 \mathrm{~cm} \pm 1.237$. Foramen index of right and left sides were $32.99 \pm 1.87$ and $34.36 \pm 6.24$ respectively. While, Udaya [9] reported a foramen index of 30.60 \pm 3.804 and $31.45 \pm 2.906$ between right and left sides.

In our study, majority (82\%) of DNF's were found on upper $1 / 3^{\text {rd }} .18 \%$ of DNF's were found on middle $1 / 3^{\text {rd }}$ and none were found on the lower $1 / 3^{\text {rd }}$. This correlates with previous studies [2, 9]. Whereas, Swati Gandhi [4] reported all the DNF's to be on the upper $1 / 3^{\text {rd }}$ (Table 6). In our study the majority of nutrient foramina were located lateral to vertical line, followed by on the line. The results correlate with previous studies [4, 9] (Table 5). Scarcity of nutrient foramina in the middle and lower $1 / 3^{\text {rd }}$ of the shaft indicates poor blood supply to this region of bone which may account for delayed union or non union of the fractures at the lower part of the bone.

The present study was done on the small sample size. The age and gender differences were not taken into consideration for the study. The morphology of nutrient foramina might be altered in males and females. Sample of long bones confined to a specific age group would be better as the nutrient foramina of the long bones might be altered during growth. Hence further studies carried on with a larger sample size would provide larger dataset which will outline the relationship and significance of number, size and location of nutrient foramen with bone metabolic activity level, static and dynamic stresses on different zones or segment of bone.

\section{Conclusion}

The nutrient foramen reflects the vascularity of a long bone; vascularity plays an important role in fracture healing. As the distribution of nutrient foramen varies from region to region, race, species, our study adds to the data of other studies of tibia in coastal region by other authors. It gives knowledge about the distribution of nutrient foramina in north and south Indian tibiae, which helps the clinicians in the treatment of tumour resection, dealing with tibial fractures from different regions. Our study concludes that nutrient foramina being scarce in the lower region of tibial shaft, fractures at lower end of tibia are prone for delayed union or non union.

Funding: Nil, Conflict of interest: None initiated, Permission from IRB: Yes 


\section{References}

1. Roger W Soames, Skeletal system, in: Gray's Anatomy $38^{\text {th }}$ ed. Edinburgh, Churchill livingstone. 1996; p. 469.

2. Ankolekar VH, Quadros LS, D'souza AS. Nutrient foramen in tibia - A study in coastal region of Karnataka. IOSR Journal of Dental and Medical Sciences. 2013; 10(3): 75-79.

3. Gopala Krishna K, Rathna BS. The study on the incidence and direction of nutrient foramina in the diaphysis of femur bone of south Indian origin and their clinical importance. International Journal of Basic and Life Sciences 2014; 2(2): 11-19. ISSN (Online): 2320$513 X$.

4. Gandhi Swati, Singla RK, Suri RK, Mehata V. Diaphyseal nutrient foramina of adult human tibia - its positional anatomy and clinical implications. Rev Arg de Anat Clin. 2013; 5(3): 222 -228.

5. Tejaswini HL, Shetty K, Dakshayani KR. Anatomic study of nutrient foramina in the human tibia and their clinical importance. International Journal of Recent Trends in Science and Technology. 2014;9(3):334- 336.

6. Menck J, Döbler A, Döhler JR. [Vascularization of the humerus]. Langenbecks Arch Chir. 1997; 382(3): 123-7.

7. Dr.Shamsunder Rao V, Jyothinath Kothapalli. The diaphyseal nutrient foramina architecture- A study on the human upper and lower limb long bones. Journal of Pharmacy and Biological Sciences. 2014; 9(1): 36-41.

8. HUGHES H. The factors determining the direction of the canal for the nutrient artery in the long bones of mammals and birds. Acta Anat (Basel). 1952; 15(3): 261-80.

9. Udaya K, Sarala Devi KV, Sridhar J. Analysis of nutrient foramen of tibia - South Indian population study. Int J Cur Res Rev. 2013; 5(8): 91-98.

10. Longia GS, Ajmani ML, Saxena SK, Thomas RJ. Study of diaphyseal nutrient foramina in human long bones. Acta Anat (Basel). 1980;107(4):399-406.

\section{How to cite this article?}

Jayaprakash T. Morphologic study of nutrient foramina in dried tibia and its clinical implications. Int J Med Res Rev 2016;4 (7):1194-1198.doi:10.17511/ijmrr.2016.i07.20. 